\title{
ist \\ Razão e historicidade no último Husserl
}

\author{
Marcella Marino Medeiros Silva
}

O texto "Die Naivität der Wissenschaft" (A ingenuidade da ciência), cuja tradução se segue, consiste em notas de trabalho escritas provavelmente no outono de 1934, época em que Husserl se ocupava sobretudo com a temática concernente a sua última grande obra publicada em vida, A crise das ciências europeias e a fenomenologia transcendental, editada em 1954 por Walter Biemel. Ele está inserido no volume xxix da Husserliana, o qual reúne textos que permitem, segundo seu editor Reinhold Smid, acompanhar o desenvolvimento do pensamento de Husserl entre 1934, e 1937 em torno da problemática da Krisis e entrever como o autor pretendia dar continuidade a seu trabalho (cf. Smid, 1993, p. xI).

Pretendemos tomar como fio condutor nesta apresentação a ideia concebida por Husserl de um questionamento necessário tanto da razão, enquanto subjetividade produtora e validadora de sentidos, quanto da historicidade, enquanto estrutura da gênese dos sentidos imanente à filosofia e às ciências, a fim de tornar claro em que medida a não tematização dessas questões conferem às ciências de um modo geral e à filosofia o caráter de ingenuidade. Husserl não pretende aqui, como veremos, invalidar os resultados apresentados nas ciências, mas sim apontar para seu caráter essencialmente relativo ao homem racional, relatividade que carece de explicitação e clarificação.

Nos primeiros parágrafos da A crise das ciências, Husserl nos apresenta um diagnóstico histórico da situação tanto das ciências quanto da filosofia a partir da segunda metade do século xix: é claro o contraste entre a cientificidade das ciências positivas e a não cientificidade da filosofia (cf. 1954, p. 2). No caso das ciências, constata-se uma total desconsideração das questões concernentes ao homem, as quais "ultrapassam $o$ mundo enquanto universo dos meros fatos" (p. 7) - trata-se aqui das chamadas questões últimas, metafísicas: ao se voltar exclusivamente às questões de fato, as ciências já não têm nada a dizer sobre a razão e a não razão; nesse sentido, afirma Husserl, "o positivismo decapta por assim dizer a filosofia" (p. 7).

Segundo o autor, essa situação não se deve apenas aos constantes fracassos da metafísica contrastados aos êxitos teóricos e práticos das ciências positivas; sua principal razão consistiu na dissolução do ideal de uma filosofia universal tal como foi con- 
cebido na modernidade filosófica, dissolução esta que, embora não possa enfraquecer os êxitos das ciências, acaba por abalá-los no que diz respeito ao seu sentido de verdade, ou seja, a sua fundamentação filosófica. A perda da crença em uma filosofia universal implica a perda da crença na razão e consequentemente da finalidade ideal de se atingir a verdade: essa tarefa tida ingenuamente como óbvia em todas as filosofias se torna incompreensível, e o problema da correlação entre o mundo e o ser em geral passa a ser o enigma de todos os enigmas.

Tendo em vista essa situação, a qual é caracterizada por Husserl como "uma penosa contradição existencial”, ele se pergunta como é possível se ater à crença na possibilidade da tarefa da filosofia, ou seja, na possibilidade de um conhecimento universal, da qual ele, enquanto filósofo autêntico, não pode abrir mão. A conclusão a que chega nesse questionamento é a de que a resposta não poderá vir da crítica comum a toda a história da filosofia, a saber, da crítica isolada de um sistema filosófico ou de uma visão de mundo, mas apenas de uma compreensão da totalidade de sua história. Não se trata aqui de uma história de fatos, mas de uma história interna, a saber, da reflexão crítica acerca daquilo que se pretendeu originalmente e através dos tempos como tarefa filosófica, reflexão esta que, segundo Husserl, permitirá o desvelamento de sua teleologia oculta. É desse modo que se concebe em $A$ crise das ciências a possibilidade e a tarefa de uma nova filosofia a partir da clarificação de todos seus pressupostos inquestionados: trata-se, para ele, de uma tomada de consciência que levará à evidenciação da tarefa, a qual dará ensejo a sua "fundação final" [Endstiftung] (Husserl, 1954, p. ₹3), inerente a qualquer fundação original. Nesse sentido, afirma Husserl, é a esta filosofia a que "toda a filosofia do passado, embora inconsciente de si mesma, estava direcionada" (1954, p. 17).

Não cabe aqui refazer, ainda que em linhas gerais, todo o percurso reflexivo apresentado em $A$ crise das ciências, mas apenas chamar a atenção para a caracterização geral do sentido da filosofia moderna enquanto conflito entre as ideias de objetivismo e transcendentalismo, o que constitui, segundo Husserl, uma unidade que se direciona "a uma forma última da filosofia transcendental enquanto fenomenologia" (1954, p. 71). A marca do objetivismo consistiria na busca filosófica e científica da verdade em si, não relativa, válida para todos os homens racionais, marca que teria sua origem na antiga separação entre doxa e episteme e na depreciação da primeira em favor da última (cf. 1954, p. 7o). No transcendentalismo, por sua vez, todo o sentido e validade do mundo pré-científico seriam provenientes da subjetividade produtora, assim como as formações de sentido de nível superior do mundo da ciência. Desse modo, o próprio mundo e a verdade objetiva apenas poderiam ganhar sentido por meio do questionamento dessa subjetividade (cf. Husserl, 1954, p. 70). Esse motivo transcendental, cuja origem se encontra em Descartes e que conduziu ao questionamento "da fonte última 
RAZÃo e historicidade No Último Husserl

de todas as formações do conhecimento, da tomada de consciência do sujeito do conhecimento de si mesmo e de sua vida de conhecimento" (1954, p. 100), será levado a cabo por Husserl em sua fenomenologia transcendental, a qual investigará o reino subjetivo "atuante em todo experienciar, pensar e viver" (p. 114), que se manteve anônimo por toda a história da filosofia, a qual, por isso mesmo, não pôde "realizar o sentido de sua fundação original enquanto ciência universal e de fundamentação última" (p. 114).

Nesse sentido, o caminho proposto por Husserl consiste em apontar para a ingenuidade imanente ao objetivismo, que tem sua origem na Grécia, com o surgimento da humanidade filosófica, a qual confere um valor maior à ideia de verdade objetiva, por oposição ao conhecimento e à verdade da doxa, e que posteriormente culmina na modernidade com a ideia de uma ciência que abarcaria todo conhecimento possível em sua infinitude (cf. Husserl, 1954, p. 124). O sentido da verdade objetiva é determinado aqui pelo contraste às verdades obtidas no âmbito da vida comum, da experiência sensível, a qual é sempre pré-dada e relativa ao sujeito. No entanto, esse âmbito, afirma Husserl, é "o solo permanente de validades, uma fonte sempre pronta de obviedades, a que nós, enquanto homens práticos ou cientistas, recorremos sem mais" (Husserl, 1954, p. 124) e a ciência, enquanto produção humana, pressupõe esse solo, embora confira a ele em sua orientação temática o status de relatividade subjetiva, a qual deve ser ultrapassada. Assim, afirma Husserl: "enquanto o cientista da natureza se volta deste modo à objetividade e está em atividade, aquilo que é relativo ao sujeito não atua apenas como uma passagem irrelevante, mas como fundamento último da validez lógicoteórica do ser para toda comprovação objetiva e, portanto, como fonte de evidência e comprovação" (1954, p. 128).

Husserl aproxima aqui o caráter das verdades produzidas no mundo científico ao caráter das verdades do mundo-da-vida, as quais são essencialmente relativas à subjetividade e sempre passíveis de comprovação e correção tanto no nível subjetivo quanto no nível intersubjetivo, o que exclui a possibilidade de uma verdade e de um mundo em si:

mundo e ser, mundo em geral só tem sentido na medida em que é ser para nós enquanto visada e experiência e mundo é sentido válido [geltender Sinn] e nada mais que sentido válido ao infinito na relatividade do valer, e (...) correlativamente, o ente [Seiendes] é apenas e por princípio ente na relatividade do valer, ou na relatividade de princípio do comprovar (Husserl, 2008, p. 725),

e, "portanto, uma coisa que é em absoluto e assim um mundo que é universalmente em absoluto são um nonsens" (p. 725). 
Dessa forma, Husserl se refere no texto "A ingenuidade da ciência" ao pressuposto da possibilidade de uma verdade em si como caracterizando uma ingenuidade do cientista, que, ao se voltar exclusivamente à prática científica e aos seus fins, deixa de lado todas as questões acerca do sentido do fazer científico. Essa ingenuidade só pode ser desfeita a partir de uma reflexão radical sobre a vida da consciência enquanto fonte constituidora de todos os sentidos. Essa reflexão, contudo, não pode ter lugar nas ciências objetivas: ela consistirá em uma ciência de caráter peculiar, visto que não supõe a postulação de uma verdade objetiva, mas que "enquanto fundamentação última" (Husserl, 1954, p. 127) é superior às ciências objetivas.

Husserl já havia apresentado em suas Ideias I (1913), como se sabe, uma reflexão fenomenológica sobre a vida da consciência enquanto instância constituidora dos sentidos. Essa fenomenologia, contudo, não levava em consideração a dimensão histórica da subjetividade; Husserl afirma posteriormente: "uma introdução sistemática completa da fenomenologia só pode começar e ser executada enquanto um problema histórico universal" (1993, p. 426). Nesse sentido, toda cultura pressupõe a dimensão de culturas passadas, o que implica uma unidade que perpassa todas as tradições até a atualidade, unidade cuja estrutura essencial pode ser revelada a partir de um questionamento metódico (1954, p. 378). A história, entendida por Husserl como movimento vivo de formação e sedimentação de sentidos, possui uma estrutura interna, a qual não pode ser alcançada pela história dos fatos, "visto que esta, ao tirar conclusões de modo ingênuo a partir dos fatos, não tematiza o solo dos sentidos, sobre o qual repousam essas conclusões, e nunca pesquisou o a priori estrutural normativo [gewaltig] que lhe é próprio" (1954, p. 380). Trata-se, portanto, de uma história interna, que retorna à origem, o que significa, para o autor, a investigação dos "materiais originários", das "premissas originárias (...), as quais se encontram no mundo cultural précientífico" (1954, p. 378).

No caso das ciências dedutivas, por exemplo, seria necessário reativar as atividades e os materiais pré-científicos que teriam motivado a formação dos conceitos, a fim de compreender se eles possuem um sentido autêntico: é apenas por esse caminho que se poderia atribuir a essas ciências o status de verdadeiro conhecimento do mundo e da natureza. Segundo Husserl, "infelizmente esta não é a nossa situação, nem tampouco a de toda a modernidade" (1954, p. 376): corre-se, portanto, o risco de que essas ciências que se desenvolveram através dos séculos sejam inautênticas.

Tendo isso em vista, o autor atribui à prática científica em "A ingenuidade da ciência" uma falha decorrente da desconsideração da historicidade das ciências: ele não quer dizer com isso que o cientista não conheça a história das ciências ou não reconheça que está inserido em uma tradição, mas sim que não lhe é clara a diferença entre a evidência obtida no método operatório, a que se pode chegar a partir do trata- 
RAZÃo E Historicidade No Último HuSSERL

mento rigoroso dos conceitos e proposições prontas, e a evidência da gênese das idealidades originárias descrita por Husserl, a qual é, no caso da geometria, por exemplo, confundida com evidência obtida com a simples representação sensível dos conceitos (cf. 1954, p. 376).

Cabe aqui mencionar uma outra questão abordada por Husserl em "A ingenuidade das ciências", a saber, a tecnicização das ciências e seu desprendimento em relação ao sentido original das idealidades, o qual foi ensejado pelos enormes êxitos práticos alcançados tanto pela geometria aplicada quanto pela matemática. Aqui, a utilidade tornou-se o principal critério para a valorização das ciências, o que, segundo o autor, configura um "desvio" ameaçador da finalidade original da ciência, ou seja, a finalidade de ser um conhecimento do mundo.

Fizemos aqui um breve esboço dos principais temas tratados por Husserl no texto que se segue, a saber, das duas ingenuidades que atribui à ciência: a primeira, como buscamos mostrar, decorre da não tematização do pressuposto da razão, e a segunda provém da desconsideração de sua historicidade, entendida como processo da gênese de idealidades sobre o solo do mundo-da-vida. O leitor se deparará, contudo, com algumas passagens obscuras, as quais atribuímos a um certo caráter fragmentado do texto, que, por consistir em anotações de trabalho, Husserl não pretendia publicar.®

\author{
Marcella Marino Medeiros Silva \\ Mestranda do Departamento de Filosofia, \\ Universidade de São Paulo, Brasil. \\ marcella_brasil@hotmail.com
}

\title{
REFERÊNGIAS BIBLIOGRÁFIGAS
}

Biemel, W. (Ed.). Husserliana. Haag: Martinus Nijhoff, 1954. v. 6.

Husserl, E. Die Krisis der europäischen Wissenschaften und die transzendentale Phänomenologie. In: BiemeL, W. (Ed.). Husserliana. Haag: Martinus Nijhoff, 1954.v. 6, p. 1-276.

. Die Krisis der europäischen Wissenschaften und die transzendentale Phänomenologie. Ergänzungsband. Texte aus dem Nachlass (1934-1937). In: Smid, R. (Ed.). Husserliana. Dordrecht: Kluwer Academic Publishers, 1993, v. 29, p. 1-4,28.

Die Naivität der Wissenschaft. In:

Die Krisis der europäischen Wissenschaften und die transzendentale Phänomenologie. Ergänzungsband. Texte aus dem Nachlass (1934,-1937). Smid, R. (Ed.). Husserliana. Dordrecht: Kluwer Academic Publishers, 1993. v. 29, p. 27-36.

. Die Lebenswelt. Auslegungen der vorgegebenen Welt und ihrer Konstitution. Texte aus dem Nachlass (1916-1937). In: Sowa, R. Husserliana. Dordrecht: Springer, 2008.v. 39, p. 1-735. 
Smid, R. (Ed.). Husserliana. Dordrecht: Kluwer Academic Publishers, 1993. v. 29.

. Einleitung des Herausgebers. In: (Ed.).Husserliana. Dordrecht: Kluwer Academic Publishers, 1993. v. 29, p. xi-lxv.

Sowa, R. Husserliana. Dordrecht: Springer, 2008. v. 39.

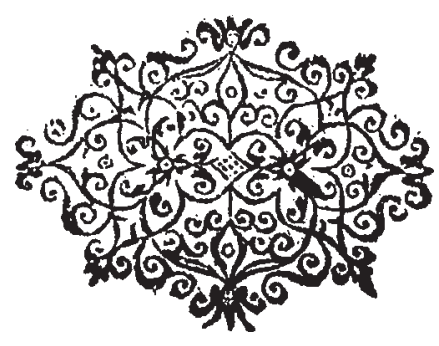

